\title{
Hydrocarbon Hydrate Flow Assurance History as a Guide to a Conceptual Model
}

\author{
E. Dendy Sloan
}

check for updates

Citation: Sloan, E.D. Hydrocarbon Hydrate Flow Assurance History as a Guide to a Conceptual Model. Molecules 2021, 26, 4476. https:// doi.org/10.3390/molecules26154476

Academic Editors: Nobuo Maeda, Zhiyuan Wang and Xiaodong Shen

Received: 28 June 2021

Accepted: 17 July 2021

Published: 24 July 2021

Publisher's Note: MDPI stays neutral with regard to jurisdictional claims in published maps and institutional affiliations.

Copyright: (C) 2021 by the author. Licensee MDPI, Basel, Switzerland. This article is an open access article distributed under the terms and conditions of the Creative Commons Attribution (CC BY) license (https:// creativecommons.org/licenses/by/ $4.0 /)$.
Department of Chemical and Biological Engineering, Colorado School of Mines, 1500 Illinois St, Golden, CO 80401, USA; esloan@mines.edu

\begin{abstract}
This work reviews major hydrocarbon hydrate advances in flowline applications of 25 international hydrate organizations. After a review of hydrate history and the current state-of-the-art, four conclusions were drawn: (1) engineers must take risks and cannot always afford the luxury to await scientific developments, (2) industry is more likely than academia to suggest hydrate needs and solutions, (3) the best hydrate blockage prevention practices are evolving and (4) a stepwise conceptual model can be proposed for a transient restart flowline hydrate blockage.
\end{abstract}

Keywords: history; flow assurance; best practices; restart; blockage; model

\section{A Brief Hydrate History \\ 1.1. Curiosity}

Curiosity and intellectual interest were the initial clathrate hydrate motivators. Hydrate discovery is usually credited to Sir Humphrey Davy [1], the mentor of Michael Faraday, in 1811. Earlier, hydrate discoverers, such as Joseph Priestley [2] did not provide reproducibility of their experiments above $273 \mathrm{~K}$, to ensure the solid discovered was not ice. European researchers discovered clathrate hydrates of natural gas and oil mixtures, as summarized in Table 1. Notably, the perseverant laboratories of de Forcrand and of Villard (1882-1925) discovered several clathrate hydrates of small hydrocarbons, such as some components of natural gas: $\mathrm{CH}_{4}, \mathrm{C}_{2} \mathrm{H}_{6}, \mathrm{C}_{2} \mathrm{H}_{4}, \mathrm{C}_{3} \mathrm{H}_{8}, \mathrm{~N}_{2}$ and $\mathrm{H}_{2} \mathrm{~S}$.

After 1925, X-ray diffraction was used to determine hydrate structures. After two decades of X-ray data, interpretation by von Stackelberg and co-workers [3-6], Claussen [7,8], and Pauling and Marsh [9] defined two hydrate crystal structures (sI and sII). Both structures are composed of the largest regular polyhedron, the pentagonal dodecahedron $\left(5^{12}\right)$ of water molecules, i.e., the basic "hydrate building block" cage containing 12 pentagon faces of hydrogen-bonded water molecules. The $5^{12}$ cavity is attached to other $5^{12}$ cavities through the $5^{12}$ vertices to compose sI (with $5^{12} 6^{2}$ cages, having two hexagonal faces in addition to the 12 pentagonal faces), or through the $5^{12}$ faces to compose sII, (with $5^{12} 6^{4}$ cages). A unique hydrate feature is that the guest molecule is trapped inside each water cage via mostly repulsive van der Waals forces, without chemical or hydrogen bonds. A pure component guest molecule smaller than n-pentane is required to prop open the water cavities and form a hydrate structure; however, mixtures can form with larger molecules. In 1952, all existing hydrocarbon hydrate structures were thought to be sI or sII. Over three decades later, a new hydrate structure (sH) was discovered by Ripmeester, et al. [10], having been overlooked in the previous data. Details of the hydrate crystal structures are in chapter two of Sloan and Koh [11].

Today scientific curiosity continues to be a major driving force in hydrate research. Rather than listing them here, scientific curiosity advances are interspersed with the following application timelines, as the hydrate history unfolds. Although there were only 22 clathrate hydrate publications from 1811 to 1834, the time of their discovery in hydrocarbon flow channels, intellectual interest and curiosity remain today as principal motivating factors in hydrate research. 
Table 1. Hydrates from 1810 to 1934. Abstracted from pg. 4 of Sloan and Koh [11].

\begin{tabular}{|c|c|}
\hline Year & Event \\
\hline 1811 & Chlorine hydrate discovery by Sir Humphrey Davy \\
\hline 1823 & Corroboration by Faraday-proposed formula $\mathrm{Cl}_{2} \bullet 10 \mathrm{H}_{2} \mathrm{O}$ \\
\hline 1882 & $\begin{array}{l}\text { De Forcrand suggested hydration number } \mathrm{H}_{2} \mathrm{~S} \bullet(12-16) \mathrm{H}_{2} \mathrm{O} \text { and measured } 30 \text { binary hydrates of } \mathrm{H}_{2} \mathrm{~S} \text { with a second } \\
\text { component such as } \mathrm{CHCl}_{3}, \mathrm{CH}_{3} \mathrm{Cl}, \mathrm{C}_{2} \mathrm{H}_{5} \mathrm{Cl}, \mathrm{C}_{2} \mathrm{H}_{5} \mathrm{Br}, \mathrm{C}_{2} \mathrm{H}_{3} \mathrm{Cl} \text {. He indicated all compositions as } \mathrm{G} \bullet 2 \mathrm{H}_{2} \mathrm{~S} \bullet 23 \mathrm{H}_{2} \mathrm{O} \text { where } \\
\qquad \mathrm{G}=2 \text { nd guest molecule (other than } \mathrm{H}_{2} \mathrm{~S} \text { ) }\end{array}$ \\
\hline 1884 & Le Chatelier showed the $\mathrm{Cl}$ hydrate $\mathrm{P}-\mathrm{T}$ curve changes slope at $273 \mathrm{~K}$ \\
\hline 1884,5 & $\begin{array}{l}\text { Roozeboom postulated lower/upper hydrate quadruple points }\left(\mathrm{Q}_{1}=\mathrm{I}-\mathrm{L}_{\mathrm{w}}-\mathrm{H}-\mathrm{V}, \mathrm{Q}_{2}=\mathrm{L}_{\mathrm{w}}-\mathrm{H}-\mathrm{V}-\mathrm{L}_{\mathrm{HC}}\right) \text {, using } \mathrm{SO}_{2} \text { as } \\
\text { evidence; determined univariant dependence of } \mathrm{P} \text { on } \mathrm{T}\end{array}$ \\
\hline 1888 & Villard obtained the temperature dependence of $\mathrm{H}_{2} \mathrm{~S}$ hydrates \\
\hline 1888 & De Forcrand and Villard measured temperature dependence of $\mathrm{CH}_{3} \mathrm{Cl}$ hydrate \\
\hline 1888 & Villard measured hydrates of $\mathrm{CH}_{4}, \mathrm{C}_{2} \mathrm{H}_{6}, \mathrm{C}_{3} \mathrm{H}_{8}, \mathrm{C}_{2} \mathrm{H}_{2}, \mathrm{~N}_{2} \mathrm{O}$ \\
\hline 1890 & $\begin{array}{l}\text { Villard measured hydrates of } \mathrm{C}_{3} \mathrm{H}_{8} \text { and suggested that the temperature of the lower quadruple. Point }\left(\mathrm{Q}_{1}\right) \text { decreased by } \\
\text { increasing the molecular mass of a guest; Villard suggested hydrates were regular crystals }\end{array}$ \\
\hline 1896 & $\begin{array}{l}\text { Villard measured hydrates of Ar and proposed that } \mathrm{N}_{2} \text { and } \mathrm{O}_{2} \text { form hydrates; Used heat of formation data to get the } \\
\text { water/gas ratio }\end{array}$ \\
\hline 1897 & $\begin{array}{c}\text { De Forcrand and Thomas sought double (w/ } \mathrm{H}_{2} \mathrm{~S} \text { or } \mathrm{H}_{2} \mathrm{Se} \text { ) hydrates; found mixed (other than } \mathrm{H}_{2} \mathrm{~S}_{\mathrm{x}} \text { ) hydrates of } \\
\text { numerous halohydrocarbons mixed with } \mathrm{C}_{2} \mathrm{H}_{2}, \mathrm{CO}_{2}, \mathrm{C}_{2} \mathrm{H}_{6}\end{array}$ \\
\hline 1902 & De Forcrand first used Clausius-Clapeyron relation for $\Delta \mathrm{H}$ and compositions; tabulated 15 hydrate conditions \\
\hline 1919 & Scheffer and Meyer refined Clausius-Clapeyron technique as applied to hydrates \\
\hline
\end{tabular}

\subsection{Flow Assurance: From Apprehension to Avoidance to Management}

Before 1934, it was thought that hydrocarbon-water flowlines were being blocked by an unusual crystal substance, attributed to various causes with a great deal of apprehension, but without much definition. Hammerschmidt $[12,13]$ studied the German monograph of Schroeder [14] to initially determine that the water + gas, crystalline flowline plugs above the ice point were clathrate hydrates. Hammerschmidt also created a simple equation to predict the pressure-temperature $(\mathrm{P}-\mathrm{T})$ formation conditions and determined many thermodynamic hydrate inhibitors, including those commonly used today, methanol and mono ethylene glycol (MEG). The Hammerschmidt equation, still reliable as an initial first inhibition estimate, allowed the natural gas industry to change the paradigm, from one of apprehension to the avoidance afforded by thermodynamic pressure, temperature and inhibitor concentration predictions.

In 1941, Katz determined that, unlike many other natural gas pure solid precipitates, clathrate hydrate conditions could be predicted as ideal solid solutions of natural gas components. Over the next decade, this discovery motivated the Katz laboratory to generate a series of vapor-solid equilibrium charts for natural gas components, commonly called $\mathrm{K}_{\mathrm{vsi}}$ charts, where individual component $\mathrm{K}_{\mathrm{vsi}}\left(\equiv \mathrm{y}_{\mathrm{i}} / \mathrm{z}_{\mathrm{i}}\right.$, the water-free ratio of component i mole fraction in the vapor $y_{i}$ and solid $z_{i}$ ) values were a function of temperature and pressure. The use of these individual component $\mathrm{K}_{\mathrm{vsi}}$ charts is like the more common vapor-liquid $\mathrm{K}_{\mathrm{i}}$ charts, where $\mathrm{K}_{\mathrm{i}}\left(\equiv \mathrm{y}_{\mathrm{i}} / \mathrm{x}_{\mathrm{i}}\right.$, the ratio of component i mole fraction in the vapor $\mathrm{y}_{\mathrm{i}}$ and liquid hydrocarbon $\mathrm{x}_{\mathrm{i}}$ ). These $\mathrm{K}_{\mathrm{vsi}}$ charts enabled the hand calculation of the temperature and pressure of the solid hydrate plug formation and the solid dewpoint (where $\Sigma \mathrm{y}_{\mathrm{i}} / \mathrm{K}_{\mathrm{i}}=1$ ). Examples of the use of both the Katz $\mathrm{K}_{\mathrm{vsi}}$ charts and the Hammerschmidt equation are provided in pp 215-233 of Sloan and Koh [11].

It was a sincere pleasure to dine with Professor Katz in 1984, who discussed what was to evolve into the first conclusion of this work. When Professor Katz was asked, "Because many of the other natural gas precipitates were known as pure solids (e.g., ice, $\mathrm{CO}_{2}$ and $\mathrm{H}_{2} \mathrm{~S}$ ) how did you arrive at the idea in 1940 that hydrates were ideal solid solutions? You didn't have the crystal structures, solid compositions, spectroscopic information, or 
a statistical thermodynamic model", Professor Katz replied, after a moment, "You know, when one doesn't have such sophisticated tools, one just has to think!".

The above, startling response was not only a modest indication to Professor Katz's outstanding intuition, but also his denigration of the misbelief that engineering is only applied science. As Koen [15] suggests in his definition of the engineering method, often the science is not available to be applied, and engineers must take considered risks before the science become available, with chances of success or failure. Engineering risk-taking is frequent, particularly in the Information Technology (IT) industry. Very many successful IT entrepreneurs, have previously failed and learned from their failures.

It was only when hydrates were discovered inside [12] and outside [16] flowlines that industrial interest expanded beyond academic curiosity. Because there are many more industrial practitioners than academics, practical applications drive both interest and publications. Industry is more likely than academia to suggest hydrate needs and solutions. This second conclusion is illustrated by the exponential growth in the number of publications per decade in Figure 1; in each decade, the number of hydrate publications increased by an average factor of 2.5 in the twentieth century. The semi-logarithmic plot of Figure 1 is not quite linear; the slope increases in 1934, the year of hydrate discovery in flowlines, and again in 1965, the year of hydrate discovery in nature.

Figure 1 provides evidence that industry is more likely than academia to suggest hydrate needs and solutions, because energy applications motivate industrial interest. Both hydrate applications increased the publication rate due to the need for energy, one of the largest drivers of a national gross domestic product (GDP), which is one measure of national economic success. Over the 30-year life of the triennial International Conference on Gas Hydrates, interest has shifted to the point that more than 80 percent of attendees are interested primarily in hydrated energy recovery.

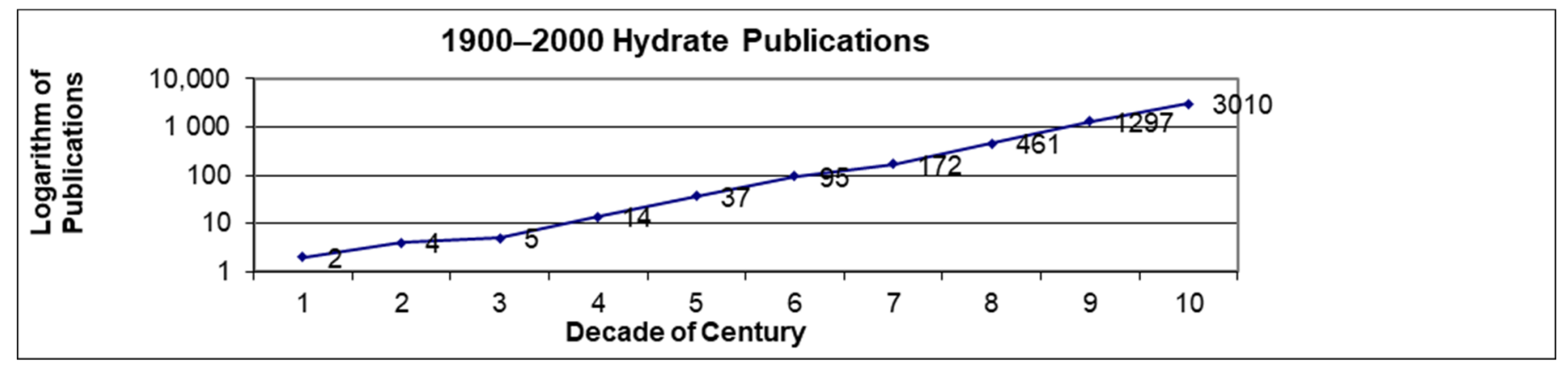

Figure 1. Base 10, semi-logarithmic plot of the number of hydrate publications by decade, from 1900-2000. Note the increases in slopes about 1934 and 1965, the years of hydrate discovery inside and outside of flowlines, respectively.

\subsection{A Statistical Theory of Hydrate Thermodynamics}

It was only after the determination of hydrate structures I and II, composed of singly occupied guests in well-defined water cavities, that a statistical theory was generated for the solid hydrate phase, by van der Waals and Platteeuw [17]. The model was first successfully applied by the Kobyashi Lab [18] to gas mixtures, and then to natural gas mixtures by Parrish and Prausnitz [19]. The model was almost too good, because, for a number of years thereafter, the hydrate phase composition was predicted by the model, rather than measured.

After X-ray crystallography enabled the definition of the hydrate crystal structures, measurements of the hydrate phase occupancy awaited spectroscopic measurements, beginning with NMR by Davidson and colleagues [20] and Raman measurements by Sum et al. [21]. These measurements showed three small errors in the van der Waals and Platteeuw model: (1) guest molecule stretch cages; (2) water molecules beyond the first shell in each cage contribute to the chemical potential; and (3) cage radii vary with temperature, pressure and equilibrium fluid compositions. Such corrections allow for a 
thermodynamic prediction of hydrate formation pressures and temperature to within $10 \%$ and $1 \mathrm{~K}$, respectively.

\subsection{Beyond Thermodynamics to Kinetics: From Avoidance to Management}

In 1980, Bishnoi and colleagues began a series of kinetic studies of hydrate formation [22]. Like other time-dependent studies, at least an order of magnitude of accuracy was sacrificed, relative to thermodynamic, time-independent studies. One particularly important result was recently shown by Ripmeester [23] to summarize some of the kinetic data in three laboratories (Canadian NRC, U. Göttingen, and GFZ Potsdam). Data in Figure 2 show that solid-phase kinetics are extremely slow; small amounts of meta-stable hydrate phases persist for long duration. Nevertheless, kinetics results permitted the hydrate paradigm change, from (1) Apprehension to (2) Avoidance and, finally, to (3) Management (Sloan [24]).

A

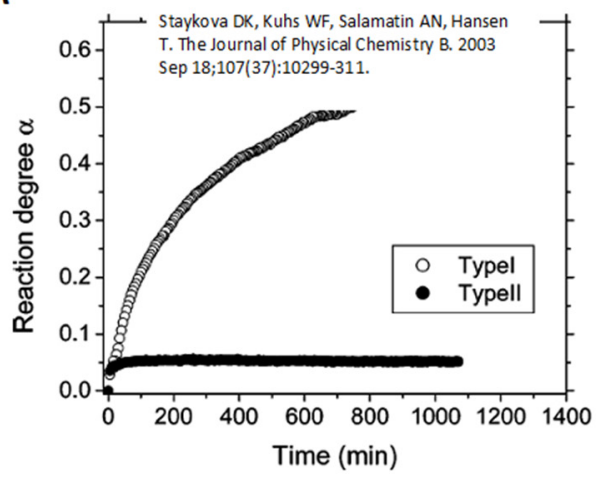

C

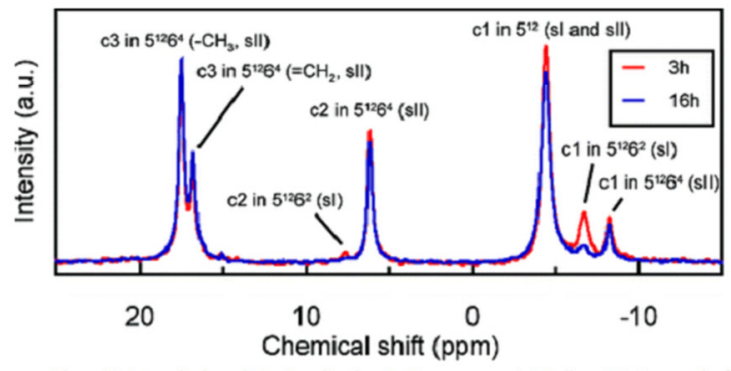

Ohno H, Moudrakovski I, Gordienko R, Ripmeester J, Walker VK. Journal of Physical Chemistry A. 2012 116(5):1337-43.
B

$\mathrm{SI} \mathrm{CO} 2+$ trace sll $\mathrm{CO} 2$

sll $\mathrm{C} 1,2,3+$ trace $\mathrm{sl} \mathrm{C} 1,2$

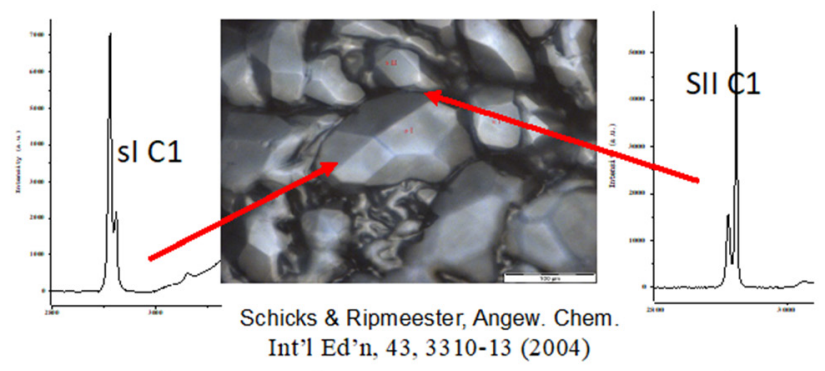

\section{D}

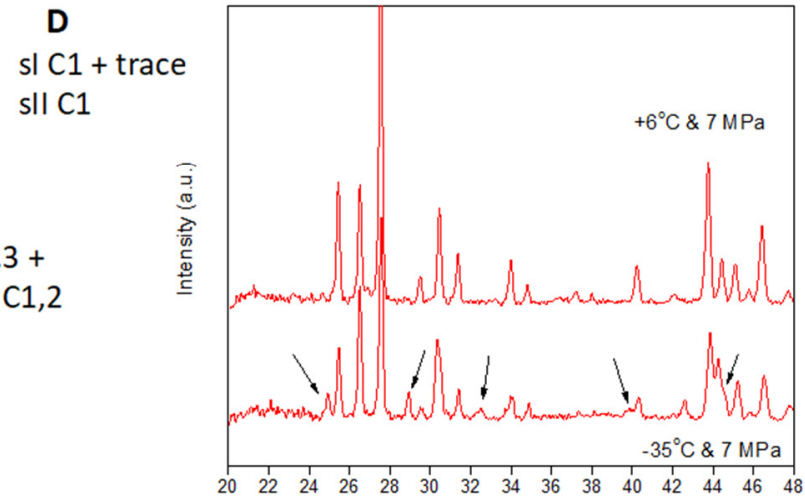

Figure 2. Spectroscopic data from Canadian NRC (C,D), U. Göttingen (A) and GFZ Potsdam (B), showing metastable hydrate phases after two days (Ripmeester [23]).

\subsection{Modern Hydrate Advances}

Table 2 summarizes some of the modern hydrate flow assurance developments. Due to space limitations, the advances in Table 2 are listed, not discussed; a thorough discussion of each development would likely require individual monographs.

Table 2. Modern hydrate flow assurance developments.

\begin{tabular}{cc}
\hline Year & Events \\
\hline 1966 & NMR measurements of the hydrate phase by Davidson and Ripmeester \\
\hline 1980 & Kinetics study begun (Bishnoi et al.) \\
\hline 1982 & 1st flowloop constructed (Sintef in Norway) \\
\hline 1987 & New structure H (sH) hydrates discovered (Ripmeester et al.) \\
\hline 1995 & Kinetic inhibitors (KHI) used in North Sea (BP) \\
\hline 1996 & Raman measurements of hydrates (Colorado School of Mines[CSM])
\end{tabular}


Table 2. Cont.

\begin{tabular}{cc}
\hline Year & Events \\
\hline 1990 's & Extended tiebacks eliminated tension leg platform need (DeepStar) \\
\hline 1999 & Hydrates declared major deep water problem for flow assurance (DeepStar) \\
\hline 2000 & Anti-agglomerates used in Gulf of Mexico for Water Cuts $($ WC $)<50 \%($ Shell) \\
\hline 2001 & Initial kinetics model enable change from avoidance to management (Shell) \\
\hline 2002 & For P < 275 bara prediction accuracy is to within 1K and 10\% P \\
\hline 2003 & Formation of plug incorporated in flow simulators (OLGA) \\
\hline 2003 & Very slow (>1000 min) conversion of metastable hydrate structure (Göttingen, Potsdam, NRC) \\
\hline 2003 & Cold Flow (BP, XoM) \\
\hline 2007 & Acoustic plug locator (Heriot-Watt) \\
\hline 2008 & N 2 used for plug removal (BP) \\
\hline 2010 & Formation risk monitoring and detection methods (Heriot-Watt) \\
\hline 2010 & Electrical heating for plug removal \\
\hline 2012 & Hydrate plug resistant oil protocols (Petrobras, Shell) \\
\hline 2012 & KHI recovery and reuse methods (Heriot-Watt) \\
\hline 2014 & Hest practices established for prevention/removal (Statoil/Equinor) \\
\hline
\end{tabular}

\subsection{The Evolution of Best Practices for Hydrate Flow Assurance}

Equinor (formerly Statoil) has explicitly complied best engineering practices for hydrate flow assurance, initially by Kinnari et al. [25]. The concept of "best practices" is very important in engineering, not only because they represent years of engineering experience, but also because best practices determine litigation outcomes. Hydrate flow assurance best practices fall into five broad categories shown in Figure 3:

1. Process Solutions: (a) remove the water and (b) dehydrate the gas.

2. Hydraulic Methods: (a) dense phases, (b) compression, (c) depressurization, (d) gas sweep and (e) fluid displacement.

3. Thermal Methods: (a) Insulation, (b) direct electrical heating, (c) pipe bundles and d) heat tracing.

4. Chemical Methods: (a) alcohols, (b) glycols, (c) low dosage inhibitors (KHIs and AAs) and (d) salt.

5. No Hydrate Control Measures: (a) low amounts of subcooling, (b) natural kinetic growth inhibition and (c) natural transportability methods.

The rightmost portion of Figure 3 represents the evolution of hydrate control methods. as kindly provided by Equinor (Li et al. 2019). A comparison of both the left and right portions of Figure 3 suggests two things: (a) the above five basic categories of flow assurance are still appropriate; and (b) industry is trending toward safe operation in the hydrate domain, using modern tools which will allow management of hydrate formation to prevent blockages. In addition to the five major control methods above, new modeling methods go beyond thermodynamic equilibrium, using time-dependent kinetic phenomena. As a result, the paradigm for hydrate flow assurance has had two major shifts: (1) first from apprehension to thermodynamic avoidance in 1934, and (2) a second time from thermodynamic avoidance toward kinetic management, beginning around 2000. 


\section{A}

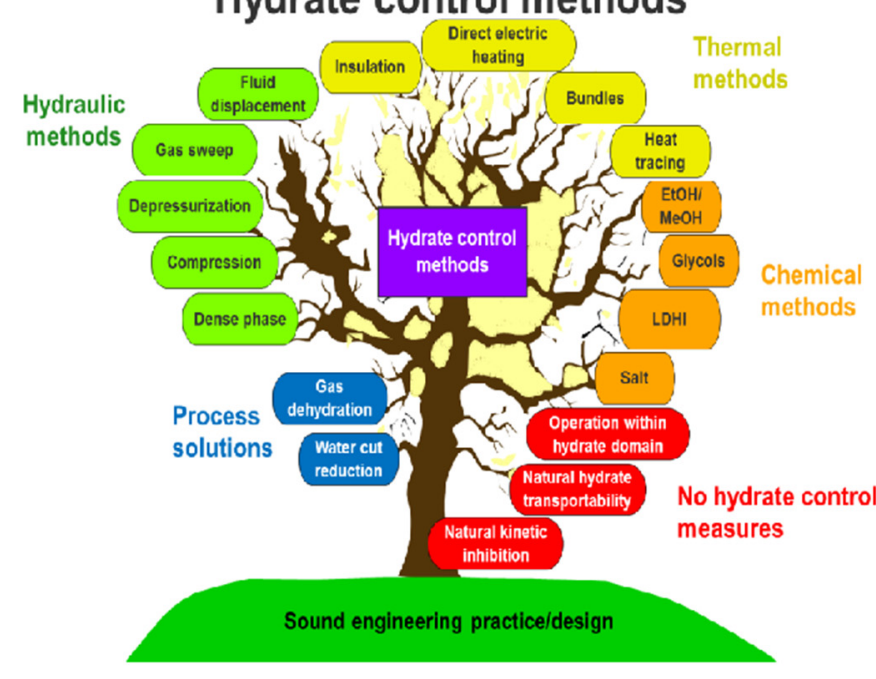

B

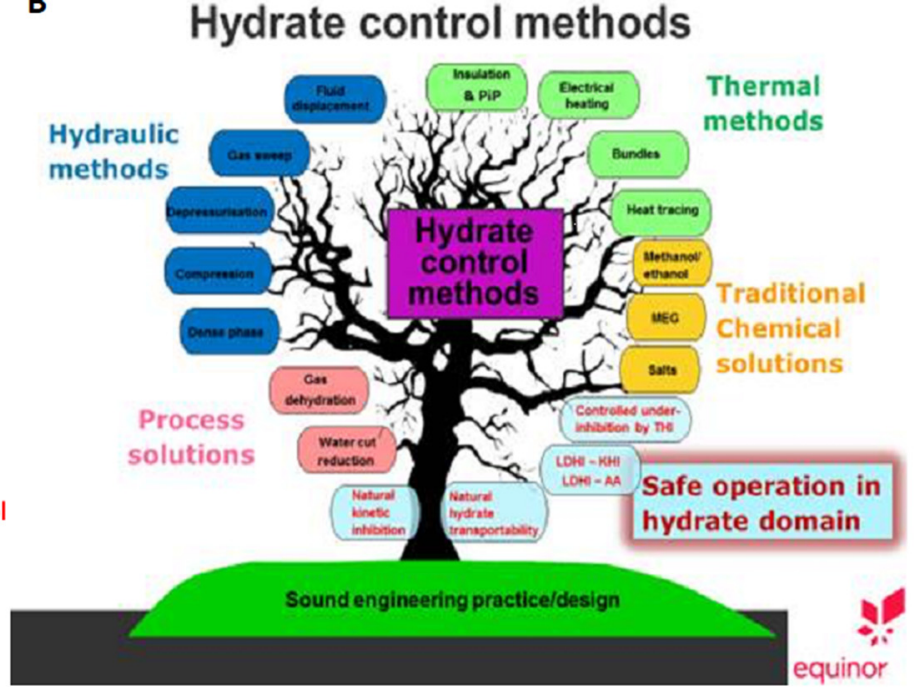

Figure 3. Equinor's concept of hydrate flow assurance best practices in 2014 (A) and 2019 (B). Note the lower rightmost methods, are trending toward a "do nothing" strategy (Li, et al., [26]).

\section{Conceptual Stages of Hydrate Plug Formation on Transient Restart}

With the evolution of experiments in the laboratory, the pilot flowloops and with field experiments, conceptual models have arisen which might enable hydrate flow assurance. As one example, the following conceptual word picture is an effort to synthesize transient hydrate laboratory, flowloop and field experiments over a number of decades. The experimental data for much of the following conceptual picture are summarized in theses from the Colorado School of Mines, particularly the theses of Pickarts [27] and Ismail [28].

Like most conceptual syntheses, some of the details are perhaps incorrect. For those potential errors and unintended slights of other laboratories, the author apologizes in advance for choosing the most familiar experimental evidence. However, the evidence seems sufficient to synthesize an initial conceptual picture for transient startup hydrate blockage formation in a low surfactant oil and gas flowline.

In normal offshore flowline operation, hydrates do not form, due to temperatures, pressures and concentrations outside hydrate thermodynamic conditions. Reservoir fluids, including progressive water amounts, are at sufficiently high temperature and pressures, so production will reach the platform as fluids, frequently aided by flowline insulation or inhibitor injection at the wellhead. Nevertheless, substantial heat is transferred from the flowline to the surrounding water at $\sim 277 \mathrm{~K}$, typically below $1200 \mathrm{~m}$ of water depth.

When flow stops, for example, due to failure of platform equipment, e.g., a compressor, a separator or a dehydrator, there is a "no touch" time of about half a day, while the platform repair process attempts to resume steady state operation. During this time, the pressurized flowline cools, approaching the hydrate stability region at the seafloor temperature of $277 \mathrm{~K}$.

For flow interruptions longer than the "no touch" time, efforts will be made to prevent flowline hydrate formation, for example, using a fluid displacing dead oil in the pipeline ("bull heading"), or by depressurizing the pipeline to remove it from the hydrate pressure at $277 \mathrm{~K}$. The following scenario for hydrate formation suggests a conceptual picture of what will happen if hydrates form before the flowline restarts.

When flow stops, the phases separate and pool as gas, oil and water according to density. The low-density gas $\left(<320 \mathrm{~kg} / \mathrm{m}^{3}\right)$ is at the flowline top, oil is in the middle (mineral oil 70T has a typical density of $780 \mathrm{~kg} / \mathrm{m}^{3}$ ) and water with a pure water density of $1000 \mathrm{~kg} / \mathrm{m}^{3}$ is at the bottom. Local flowline low spots encourage phase pooling, which may not represent the overall flowline conditions.

As the pipeline subcools about $3.5 \mathrm{~K}$ into the hydrate stability condition, hydrates (density $\left.\sim 900 \mathrm{~kg} / \mathrm{m}^{3}\right)$ form an initial thin $(\sim 10 \mu \mathrm{m}$ thick) film at the oil-water interface. 
Because flowline hydrates are $85 \mathrm{~mol} \% \mathrm{H}_{2} \mathrm{O}$ with molecules smaller than $\mathrm{C}_{5} \mathrm{H}_{12}$, three things happen: (1) water-in-oil emulsions frequently break (Høiland et al. [29]); (2) hydrate formation consumes molecules smaller than $\mathrm{C}_{5} \mathrm{H}_{12}$ dissolved in the oil phase, requiring subsequent dissolution and diffusion of small gas molecules into the oil layer to reach the hydrate film at the oil-water interface; and (3) a hydrate thin film covers the water phase at the hydrocarbon interface, so that the pseudo-solid is initially as little as 4 volume per cent hydrate (Austvik [30], but anneals to a more solid mass.

Annealing initially occurs by water (not hydrocarbon) perfusion through the cracks in the hydrate film (Davies et al. [31]. The thin hydrate film is more solid than fluid, but initially in a transitional, malleable state which solidifies with time. When the flowline restarts, if sufficient time has passed for a solid hydrated mass to block the channel, the flow will stop.

However, if the hydrate is still a thin film, high startup turbulence will shear the film to form small hydrate-film-encrusted water droplets, which quickly cohere to form a larger and porous solid. Unconverted water remains as a separated layer, partitioned by the hydrate mass from the oil. Any free-water layer helps maintain movement of agglomerated hydrates. Over time, the unconverted water is infused into the hydrate mass until the free-water phase disappears.

With the disappearance of the free-water layer, the hydrate mass contacts the pipe wall as a deposit. Even with a small amount of hydrate and high porosity (85-90\%), the deposit may impede flow. With flow stopped, the mass will further anneal to a more substantial hydrate solid. At that point, corrections must be taken, such as depressurization, inhibitor injection with coiled tubing, etc.

\section{Conclusions}

Because flow assurance academic researchers are greatly outnumbered, an industrial majority of flow assurance professionals have determined many of the hydrate flow assurance solutions which have grown into hydrate prevention best practices, for example, as illustrated in Figure 3.

Over two centuries since the discovery of hydrates, experimental evidence has evolved-for example, enabling one new conceptual picture of transient restart hydrate formation in oil and gas pipelines presented at the conclusion of this work. Like most syntheses, some details will either be disputed or considered inadequate. However, the transient hydrate formation restart conceptual picture draws together much of the current experimental evidence from laboratories, flowloops and field data.

Some of the details in the transient restart hydrate formation concept require scientific verification. However, the transient restart concept may enable better flow assurance. As a minimum, the concept might serve as a basis for future corrections, considering Francis Bacon's dictum, "Truth emerges more readily from error than from confusion".

Funding: This research received no external funding.

Institutional Review Board Statement: Not applicable.

Informed Consent Statement: Not applicable.

Data Availability Statement: No new data were created or analyzed in this study. Data sharing is not applicable to this article.

Acknowledgments: A number of colleagues have kindly contributed the advances in their laboratories and countries to this admittedly incomplete history: Z. Aman (U. W. Australia), T. Austvik (Equinor), R. Bishnoi (U. Calgary, ret.), R. Boswell (USDoE), R. Carmargo (Petrobras, ret.), R. Chapman (BP, ret.), L. Chen (China), T. Collett (USGS), O. Hernandez (BP), J-M.Herri (Mines Ste. Etienne), K. Hester (Eni), C. Koh (CSM), W. Kuhs (U. Göttingen), X.Li (Equinor), P. Linga (U. Singapore), T. Makogon (Wood), Y. Makogon (dec., TAMU, Russia) A. Mehta (Shell), G. Moridis (LBNL), T. Palermo (Total), P. Prasad (India), I. Rao (Shell), J. Ripmeester (NRC, ret.), J. Schicks (GFZ Potsdam), S. Subramanian (Chevron), L. Talley (XoM, ret.), B. Tohidi (Heriot-Watt), T. Uchida (Japan). 
Conflicts of Interest: The author declares there are no conflict of interest.

\section{References}

1. Davy, H. The Bakerian lecture: On some of the combinations of oxymuriatic gas and oxygen and on the chemcial relations of these principles. Phil. Trans. R. Soc. (Lond.) 1811, 101, 1.

2. Priestley, J. Experiments and Observations on Different Kinds of Air and Other Branches of Natural Philosophy Connected with the Subject (in Three Volumes); T. Pearson: Birmingham, UK, 1790; p. 359.

3. Von Stackelberg, M. Solid gas hydrates. Naturwiss 1949, 36, 359.

4. Von Stackelberg, M.; Müller, H.R. Feste gashydrate II structur und raumchemie. Z. Electrochem. 1954, 58, 25.

5. Von Stackelberg, M. Feste gashydrate. V: Die Bindungsenergien. Z. Electrochem. 1954, 58, 104.

6. Von Stackelberg, M. Gashydrate. Rec. Trav. Chim. Pays-Bas 1956, 75, 902. [CrossRef]

7. Claussen, W.F. Suggested structures of water in inert gas hydrates. J. Chem. Phys. 1951, 19, 259. [CrossRef]

8. Claussen, W.F. A second water structure for inert gas hydrates. J. Chem. Phys. 1951, 19, 1425. [CrossRef]

9. Pauling, L.; Marsh, R.E. The structure of chlorine hydrate. Proc. Natl. Acad. Sci. USA 1952, 38, 112. [CrossRef] [PubMed]

10. Ripmeester, J.A.; Tse, J.S.; Ratcliffe, C.I.; Powell, B.M. A new clathrate hydrate structure. Nature 1987, 325, 135. [CrossRef]

11. Sloan, E.D.; Koh, C.A. Clathrate Hydrates of Natural Gases, 3rd ed.; Taylor \& Francis: Boca Raton, FL, USA, 2008.

12. Hammerschmidt, E.G. Formation of gas hydrates in natural gas transmission lines. Ind. Eng. Chem. 1934, 26, 851. [CrossRef]

13. Hammerschmidt, E.G. Preventing and removing hydrates in natural gas pipe lines. Gas Age 1939, 83, 45-49.

14. Schroeder, W. Die Geschichte der Gas Hydrate. Sammlung. Chem. Tech. Vortrage 1927, 29, 90-98.

15. Koen, B.V. Discussion of the Method: Conducting the Engineer's Approach to Problem Solving; Oxford University Press: Oxford, $\mathrm{UK}, 2003$.

16. Makogon, Y.F. Hydrate formation in gas bearing beds under permafrost conditions. Gazov. Promst. 1965, 5, 14.

17. Van der Waals, J.H.; Platteeuw, J.C. Clathrate solutions. Adv. Chem. Phys. 1959, 2, 1.

18. Saito, S.; Marshall, D.R.; Kobayashi, R. Hydrates at high Pressures: Part II. Application of statistical mechanics to the study of the hydrates of methane, argon, and nitrogen. AIChE J. 1964, 10, 734. [CrossRef]

19. Parrish, W.R.; Prausnitz, J.M. Dissociation pressures of gas hydrates formed by gas mixtures. Ind. Eng. Chem. Proc. Des. Dev. 1972, 11, 26. [CrossRef]

20. Davidson, D.W. Clathrate Hydrates. In Water in Crystalline Hydrates Aqueous Solutions of Simple Nonelectrolytes. Water (A Comprehensive Treatise); Franks, F., Ed.; Springer: Boston, MA, USA, 1973; Volume 2, pp. 115-234.

21. Sum, A.K.; Burrus, R.C.; Sloan, E.D. Measurement of clathrate hydrates via Raman spectroscopy. J. Phys. Chem. B 1997, $101,7371$. [CrossRef]

22. Bishnoi, P.R. The Kinetics of Natural Gas Hydrate Formation; Final Report Contract DSSF14SU 23235-0-0497; Department of Energy, Mines \& Resources: Ottawa, ON, Canada, 1980.

23. Ripmeester, J.A. Clathrate hydrates: The importance of fundamental research. Presented at the Conference for Youth Encouragement, Qingdao, China, 24 July 2018.

24. Sloan, E.D. A changing hydrate paradigm-From apprehension to avoidance to risk management. Fluid Phase Equilibria 2005, 67, 228-229. [CrossRef]

25. Kinnari, K.; Hundseid, J.; Li, X.; Askvik, K.M. Hydrate management in practice. Chem. Eng. Data 2014, 60, 437. [CrossRef]

26. Li, X.; Austvik, K.; Askvik, T. (Equinor ASA, Stavanger, Norway). Personal communication, 27 February 2019.

27. Pickarts, M. Hydrate Deposition Fundamentals \& Mitigation Efforts with Coatings and Hydrate Formation during Transient Shut-In/Restart Operations. Ph.D. Thesis, Colorado School of Mines, Golden, CO, USA, 2022.

28. Ismail, N. Hydrate Plugging Properties with Natural and Synthetic Anti-Agglomerants in Liquid Hydrocarbon Phase. Ph.D. Thesis, Colorado School of Mines, Golden, CO, USA, 2022.

29. Høiland, S.; Borgund, A.E.; Barth, T.; Fotland, P.; Askvik, K.M. Wettability of Freon hydrates in crude oil/brine emulsions: The effects of chemical additives. In Proceedings of the International Conference on Gas Hydrates (ICGH 5), Trondheim, Norway, 12-16 June 2005; NO-7005. Tapir Academic Press: Trondheim, Norway, 2005; Volume 4, p. 1151.

30. Austvik, T. Hydrate Formation in Pipes. Doctor Ing. Thesis, Norwegian Institute of Technology, Trondheim, Norway, 1992.

31. Davies, S.R.; Sloan, E.D.; Sum, A.K.; Koh, C.A. In situ studies of the mass transfer mechanism across a methane hydrate film using high-resolution confocal raman spectroscopy. J. Phys. Chem. 2010, 114, 1173. [CrossRef] 